\title{
Combining bimodal presentation schemes and buzz groups improves clinical reasoning and learning at morning report
}

Citation for published version (APA):

Balslev, T., Rasmussen, A. B., Skajaa, T., Nielsen, J. P., Muijtjens, A., De Grave, W., \& Van Merrienboer, J. (2015). Combining bimodal presentation schemes and buzz groups improves clinical reasoning and learning at morning report. Medical Teacher, 37(8), 759-766.

https://doi.org/10.3109/0142159X.2014.986445

Document status and date:

Published: 01/01/2015

DOI:

10.3109/0142159X.2014.986445

Document Version:

Publisher's PDF, also known as Version of record

Document license:

Taverne

Please check the document version of this publication:

- A submitted manuscript is the version of the article upon submission and before peer-review. There can be important differences between the submitted version and the official published version of record.

People interested in the research are advised to contact the author for the final version of the publication, or visit the DOI to the publisher's website.

- The final author version and the galley proof are versions of the publication after peer review.

- The final published version features the final layout of the paper including the volume, issue and page numbers.

Link to publication

\footnotetext{
General rights rights.

- You may freely distribute the URL identifying the publication in the public portal. please follow below link for the End User Agreement:

www.umlib.nl/taverne-license

Take down policy

If you believe that this document breaches copyright please contact us at:

repository@maastrichtuniversity.nl

providing details and we will investigate your claim.
}

Copyright and moral rights for the publications made accessible in the public portal are retained by the authors and/or other copyright owners and it is a condition of accessing publications that users recognise and abide by the legal requirements associated with these

- Users may download and print one copy of any publication from the public portal for the purpose of private study or research.

- You may not further distribute the material or use it for any profit-making activity or commercial gain

If the publication is distributed under the terms of Article $25 \mathrm{fa}$ of the Dutch Copyright Act, indicated by the "Taverne" license above, 


\section{Combining bimodal presentation schemes and buzz groups improves clinical reasoning and learning at morning report}

Thomas Balslev, Astrid Bruun Rasmussen, Torjus Skajaa, Jens Peter Nielsen, Arno Muijtjens, Willem De Grave \& Jeroen Van Merriënboer

To cite this article: Thomas Balslev, Astrid Bruun Rasmussen, Torjus Skajaa, Jens Peter Nielsen, Arno Muijtjens, Willem De Grave \& Jeroen Van Merriënboer (2015) Combining bimodal presentation schemes and buzz groups improves clinical reasoning and learning at morning report, Medical Teacher, 37:8, 759-766, DOI: 10.3109/0142159X.2014.986445

To link to this article: https://doi.org/10.3109/0142159X.2014.986445

\section{曲 Published online: 11 Dec 2014.}

Submit your article to this journal ¿

Џll Article views: 593

Q View related articles $\square$

View Crossmark data ¿

Citing articles: 2 View citing articles $\sqsubset$ 


\title{
Combining bimodal presentation schemes and buzz groups improves clinical reasoning and learning at morning report
}

\author{
THOMAS BALSLEV ${ }^{1,2}$, ASTRID BRUUN RASMUSSEN ${ }^{1}$, TORJUS SKAJAA ${ }^{1}$, JENS PETER NIELSEN ${ }^{1}$, ARNO \\ MUIJTJENS ${ }^{3}$, WILLEM DE GRAVE ${ }^{3}$ \& JEROEN VAN MERRIËNBOER ${ }^{3}$ \\ ${ }^{1}$ Viborg Regional Hospital, Denmark, ${ }^{2}$ Aarhus University, Denmark, ${ }^{3}$ Maastricht University, The Netherlands
}

\begin{abstract}
Morning reports offer opportunities for intensive work-based learning. In this controlled study, we measured learning processes and outcomes with the report of paediatric emergency room patients. Twelve specialists and 12 residents were randomised into four groups and discussed the same two paediatric cases. The groups differed in their presentation modality (verbal only vs. verbal + text) and the use of buzz groups (with vs. without). The verbal interactions were analysed for clinical reasoning processes. Perceptions of learning and judgment of learning were reported in a questionnaire. Diagnostic accuracy was assessed by a 20 -item multiple-choice test. Combined bimodal presentation and buzz groups increased the odds ratio of clinical reasoning to occur in the discussion of cases by a factor of $1.90(p=0.013)$, indicating superior reasoning for buzz groups working with bimodal materials. For specialists, a positive effect of bimodal presentation was found on perceptions of learning $(p<0.05)$, and for residents, a positive effect of buzz groups was found on judgment of learning $(p<0.005)$. A positive effect of bimodal presentation on diagnostic accuracy was noted in the specialists $(p<0.05)$. Combined bimodal presentation and buzz group discussion of emergency cases improves clinicians' clinical reasoning and learning.
\end{abstract}

\section{Background}

Admissions to clinical departments are often reported at morning report, a major educational and patient care-related activity in teaching hospitals (Gross et al. 1999; Amin et al. 2000; Hougtalen et al. 2002; Klaber \& Macdougall 2009; Walton \& Steinert 2010; McNeill et al. 2013). Morning report is a decisiondense, work-based learning environment, diagnostic uncertainty is common, and opportunities to practice and compare clinical reasoning are frequent. As an educational tool, however, morning report is challenging to define, and its outcomes are difficult to measure (McNeill et al. 2013). Learning needs among the participating clinicians are diverse, as they range in experience from novices (medical students) to intermediates (residents) and experts (specialists). When defining a learning theory framework for teaching and learning at morning report, the concept of cognitive apprenticeship is relevant (Collins 2006; Schumacher 2013). Cognitive apprenticeship emphasises a number of teaching and learning methods, including modelling, coaching and scaffolding. Inherently, interaction between learners and teachers is important and has the greatest impact when learners have adequate time and the curriculum permits continuity and sequenced challenges. Although morning report may indeed offer opportunities for intensive, interactive, work-based and sequenced learning from authentic cases, these learning opportunities are often neglected or unused (Walton \& Steinert 2010). We suggest that this is at least

\section{Practice points}

- Structure of morning report is important for the quality of clinical reasoning and learning.

- Bimodal presentation of selected cases combined with activation of all the participants in buzz groups increases the quality of clinical reasoning at morning report.

- Continued focus on residents' self-directed learning, coaching and modelling by specialists is required.

partly because little empiric research has been done on the teaching and learning involved at morning report (Walton \& Steinert 2010; McNeill et al. 2013).

Morning report and elaboration and guidance of clinical reasoning

According to the cognitive apprenticeship learning theory, such research should include a focus not only on learning outcomes but also on the processes of learning (Collins 2006). Therefore, an emphasis on development of medical expertise is highly relevant. We know that medical expertise develops by integration of knowledge into illness scripts, i.e.

Correspondence: Thomas Balslev, Department of Paediatrics, Regional Hospital Viborg, 8800 Viborg, Denmark. Tel: +45 $21736904 ;$ Fax: +45 7844 5434; E-mail: bafl@dadlnet.dk 
cognitive entities containing clinically relevant information (Schmidt \& Rikers 2007). This integration occurs with extensive and repeated application of knowledge during exposure to real patient problems (Schmidt \& Rikers 2007). Knowledge about pathophysiology is gradually encapsulated within the script, and the number of scripts grows with experience. Much time should therefore be spent on having learners reflect and elaborate on patients (Schmidt \& Rikers 2007). Time spent at morning report talking over cases is a valuable investment that can enhance encapsulation, illness script formation and diagnostic accuracy. In addition, research should take into account cognitive load theory (van Merriënboer \& Sweller 2005), as inappropriate presentation of patients or just too many complex patients may overload working memory and hamper performance and learning. With the addition of a written presentation scheme, a simple intervention like bimodal presentation could help learners counteract this problem by using two channels, i.e. verbal and visual, instead of verbal only (van Merriënboer \& Sweller 2005).

Recent research suggests that in contextual, authentic learning there is a need to guide not only clinical reasoning, but also visual search and attention (Jarodzka et al. 2012). Knowledge on visual skills is now available from eye-tracking studies performed in radiology and paediatrics, (Krupinski et al. 2006; Kok et al. 2012; Balslev et al. 2012) and it appears that viewing behaviour of newcomers in a specialty is strongly determined by stimulus characteristics. Viewing behaviour steered by salience of stimuli is called bottom-up behaviour (Itti \& Koch 2001). When cognitive relevance guides visual search, as is the case with experts, this is called top-down behaviour (Yarbus 1967; DeAngulus \& Pelz 2009). This line of research also supports the use of a scheme for presentation of cases to help learners attend to and process key aspects of the case.

From the problem-solving literature, it is well known that novice learners characteristically work backwards from a goal. That is, they focus on the goal and try to find means that could help them to reach this goal, a phenomenon that is also found in visual domains (van Meeuwen et al. 2014). In contrast, experts, who possess useful schemes or scripts, typically work forward from relevant, activated illness scripts towards the goal (van Meeuwen et al. 2014). There are thus a large number of lines of research to support the use of a scheme for presentation of cases to help learners attend to and process key aspects of the case. To help learners work more like experts by deliberately practicing a top-down, forward approach to cases, a bimodal presentation scheme for stepwise, daily presentation of single emergency cases was developed in paediatric departments in Denmark. The presentation scheme, named "Today's Case" (TDC), is thus designed to help the reporting residents extract the most important information from the case and present it in an organised way. TDC is also designed to enhance elaboration of clinical reasoning processes, and in this way help learners create new scripts. Although TDC may also include authentic clinical pictures or video recordings, such imaging is not tested in the present study.

\section{Improving clinical reasoning and learning by bimodal presentation schemes and buzz groups}

Clinical reasoning is the argumentation clinicians use while diagnosing clinical cases and we are very interested in this type of expertise as a process marker of learning. The aim of our research was to measure how different types of support affect participants' quality of clinical reasoning.

Clinical reasoning can be improved by scaffolding. Scaffolding offers the learner opportunities to practice while the teacher gradually fades his/her support (Puntambekar \& Hübscher 2005; Morris \& Blaney 2010; Belland 2014). We thus believe that the provision of a simple scheme with oral and written information, i.e. bimodal presentation, which is revealed with a stepwise, top-down and forward approach, will help learners deal with key aspects of a clinical case. Scaffolding can also be related to the interaction among participants that is involved in sharing of cognition (Lebeau 1998; Balslev et al. 2009), an essential feature of collaborative learning from clinical encounters. A large group can be divided into smaller groups for a short period of time to increase interaction (Cantillon 2003; Jaques 2003). These are named buzz-groups after the sound they produce when pairs actively exchange arguments (Jaques 2003). In buzz-group pairs, scaffolding can be instantaneously adapted to the levels of expertise and prior knowledge of the two clinicians (Puntambekar \& Hübscher 2005). The interaction of bimodal presentation with "buzzing" is particularly interesting. Instead of having to hold all the verbal information in working memory, participants in the buzz groups are helped by the visually available, written information (van Merriënboer \& Sweller 2005).

Diagnostic accuracy can be used as a dependent variable for learning outcome, because diagnostic accuracy is a marker for expertise. Self-assessment of learning on the other hand, is a complicated, multipurpose and a context-dependent phenomenon (Eva \& Regehr 2005; Bjork et al. 2013). In the context of morning report, we believe that two perspectives are important: how much participants think they learned from an activity (perception of learning), and their prediction of how well they will perform in a diagnostic accuracy test afterwards: judgment of learning.

\section{Development of hypotheses}

Compared to a standard situation with oral presentation of a case without planned interaction, we added: (1) bimodal presentation of Today's Case, or (2) buzz groups with one-toone interactive, collaborative analysis. Above all, we expected that clinical reasoning would improve with the combination of bimodal presentation with buzz group, as the interaction in the buzz groups would be greatly helped by the written information available throughout the discussion. We also anticipated that the perception of learning might improve with use of a bimodal presentation scheme and buzz groups. We expected judgment of learning, i.e. the predicted future performance, to be better with residents working in buzz groups due to the saliency of the cognitive apprenticeship model in one-to-one buzz group discussions. We expected that the diagnostic 
accuracy would be enhanced if a written case was available and work was done with the help of buzz groups.

We hypothesised:

(1) The combination of a bimodal presentation scheme and buzz groups yield positive interaction effects on the quality of clinical reasoning.

(2) The perception of learning improves with use of a bimodal presentation scheme and buzz groups.

(3) The judgment of learning improves with use of a bimodal presentation scheme and buzz groups.

(4) Diagnostic accuracy improves with use of a bimodal presentation scheme and buzz groups.

\section{Methods}

\section{Setting and participants}

For this study, a small scale version of morning report with controlled research circumstances was developed. A total of 24 clinicians, i.e. 12 specialists (mean duration of paediatric experience: 18.1 years) and 12 residents (mean duration of paediatric experience: 1.3 years) from 5 paediatric departments participated.

\section{Today's case}

We designed a presentation scheme for the reporting of selected single emergency room patients, TDC; see Figure 1. TDC was deliberately designed to help participants deal with key aspects of the history first, i.e. to apply a top-down, forward approach.

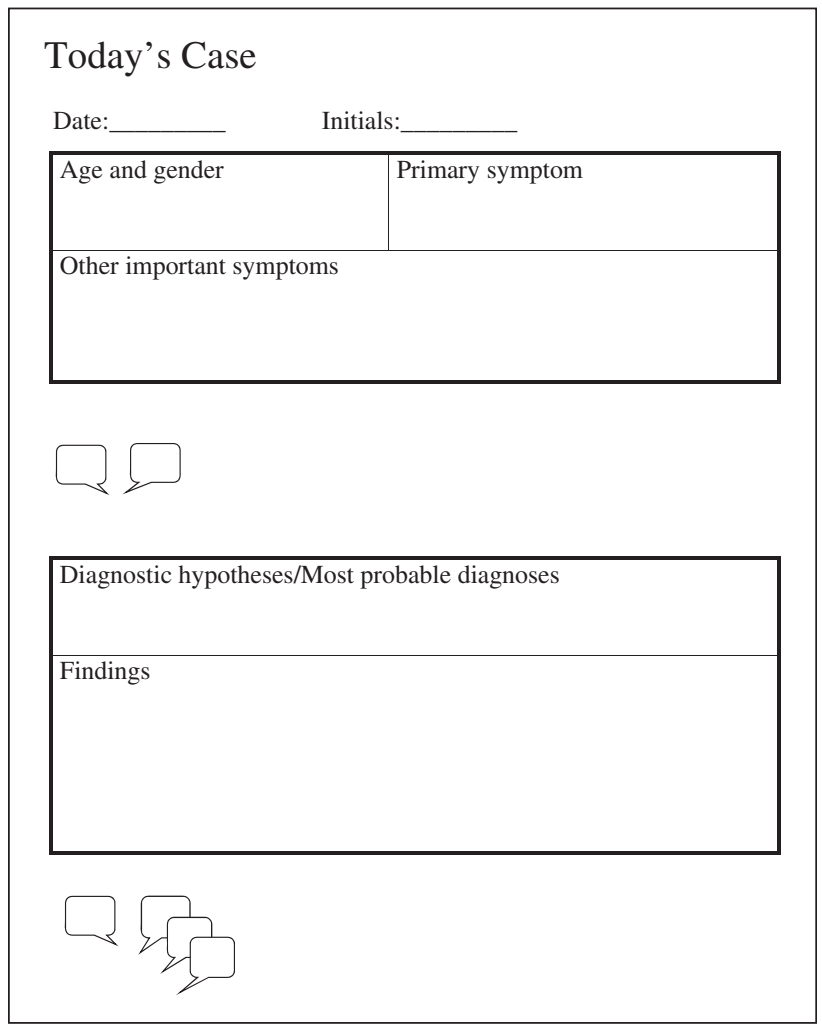

Figure 1. Today's case.
In section $\mathrm{A}$, visual information such as age, gender, primary symptom and other important symptoms were presented in writing and mentioned verbally, whereas section B was not revealed until later. The case selected should possess some diagnostic ambiguity so that extensive clinical reasoning processes might be stimulated. The resident asked for collaborative clinical reasoning in pairs ("buzz groups"). When discussion came to an end, the resident asked for comments from a few participants. In section B, the findings were revealed. A group discussion of findings and most probable diagnosis (after examination) then took place. Finally, one or two of the specialists commented on the case. Icons in the scheme indicated the formats of the discussion.

Two authentic cases were presented verbally. Case 1 had respiratory problems due to a haemangioma in the trachea. Case 2 had seizures signalling benign autonomic epilepsy (Panayiotopoulos syndrome). The cases were expected to be diagnostically challenging to the residents, while the specialists were expected to be able to recognise the key information and to make a correct diagnosis. Case 1 was presented first and analysed, then case 2. To ensure that the content of the discussion was similar, each group analysed the same two cases. To prevent dissemination of content, groups worked on the same day.

\section{Instruments and measures}

The clinical reasoning processes in the entire verbal interaction during analysis of cases were assessed by a coding system (Hassebrock \& Prietula 1992) adapted by de Grave et al. (1996). The system provides an instrument for the categorisation of cognitive processes appearing during problem analysis by groups. As this study focuses on the development of expertise by improved development of illness scripts, then enhanced theory building, theory evaluation and metareasoning are desirable (Balslev et al. 2012). On the other hand, we know that data exploration is used less with increased duration of postgraduate expertise. All verbal clauses were scored as data exploration, building of hypotheses, evaluation of hypotheses and metareasoning (Table 1) and reported in frequency tables.

The quality of clinical reasoning was assumed to be indicated by an increase of the relative frequency of clauses labelled as "building of hypotheses", "evaluation of hypotheses" or "metareasoning" versus clauses labelled as "data exploration". Hence, for the analysis regarding hypothesis 1 the categorization of clauses was transformed into a binary scheme: clinical reasoning clauses versus other clauses.

Learning outcomes were evaluated by a questionnaire and by a diagnostic accuracy test. One item tested perception of learning from the session on a 10-point Likert scale, (0: I did not learn anything new; 9: I learned very much new). One item tested prediction of performance on the subsequent diagnostic accuracy test (judgment of learning) (Bjork et al. 2013): We simply asked "As a test, you will receive 20 cases that must be diagnosed. How many of them do you expect to diagnose correctly?" The diagnostic accuracy was tested by a 20 -item MCQ test. The test was constructed by a specialist in 
Table 1. Coding system for clauses in the protocols of verbal interaction during problem analysis.

Task level

2.1 Data exploration: problem definition; reference to the information in the case; identification; structuring; integrating and initial interpretation of information; signalling lacking data

"When did it start?"

"How old is he?"

"He has two haemangiomas on the skin"

2.2 Theory building: causal reasoning; hypothesis; associations' specification; generalisation.

"It could be asthma"

"I think he has a haemangioma in the trachea"

2.3 Theory evaluation: confirming evaluation; non-confirming evaluation, evaluation about certainty.

"Yes, you are right"

"No, he is too old to have laryngomalacia"

2.4 Metareasoning: reflecting on prior knowledge, reflecting on the learning

process, reflecting on strategy of thinking

"This is how I think"

"There may be different views on that"

Representative examples are presented in italics.

paediatrics (TB) and two trainees (ABR and TS). It was designed to test diagnostic accuracy in airway obstruction in infants (case 1) and in seizures in children (case 2). Correct diagnoses were established beforehand by two expert paediatricians. The test results were scored by two researchers. The diagnostic accuracy test score was the frequency of correctly diagnosed cases.

\section{Procedures}

This was a randomised controlled study with post-test only. We provided an identical verbal stepwise presentation of patient cases to all four conditions.

We applied bimodal presentation, because human working memory has a visual as well as an auditory component that are largely independent of each other. Using both components would increase working memory capacity, with positive effects on learning. TDC ensures participants' bimodal presentation, as the participants are always able to listen to the verbal presentation, and they have a written version available. The scheme was projected onto a screen visible to the participants. Thus, participants were always able to re-read and re-evaluate information given a few seconds before. We applied buzz groups to increase the interaction among the participants. We used the ideal scaffolding modality: one-toone scaffolding. One-to-one scaffolding occurs in buzz groups, and mechanisms include questioning, feedback, indication of important problem elements and expert modelling (Belland 2014). Bimodal presentation and buzz groups were combined in a full factorial design (Figure 2).

Specialists and residents were allocated randomly to basic, buzz, bimodal or the buzz+ bimodal groups. The groups consisting of three experts and three non-experts showed no significant differences in terms of duration of paediatric experience. In groups buzz and buzz + bimodal, pairs of one specialist and one resident were randomly formed and discussed cases prior to the discussion in the larger group.

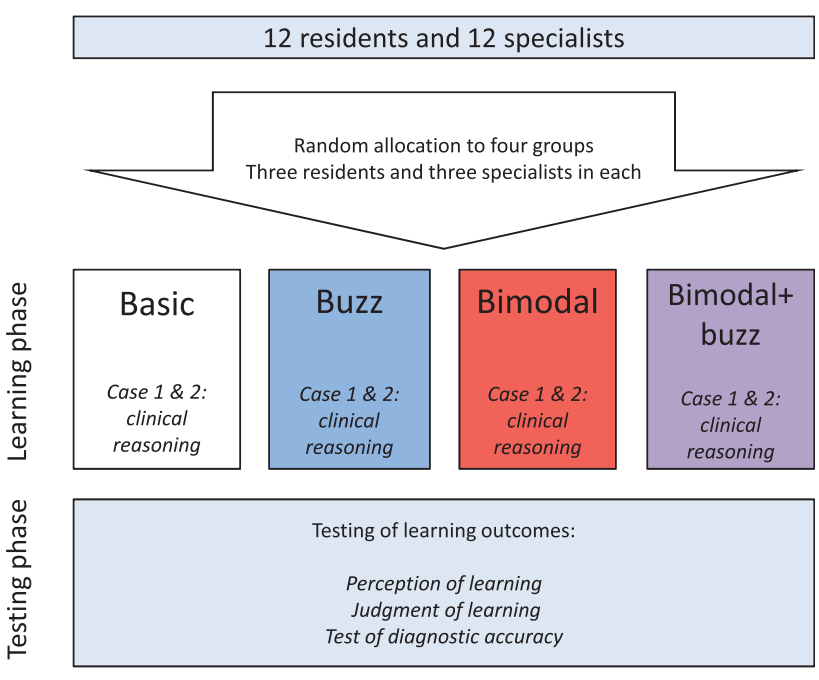

Figure 2. This flow diagram summarizes the one-day study process.

In groups basic and bimodal, buzz group discussion was omitted. Informed, written consent was obtained from all participants. The procedure was verbally and graphically explained to each group to ensure that participants were familiar with the setup. Participants were instructed to discuss information in such a way, that the residents verbalised their thoughts first. Immediately after the learning phase, participants filled in a questionnaire.

\section{Data collection and analysis}

The verbal interaction from the beginning to the end of the analysis of cases, including the interactions in buzz group discussions, was recorded on multiple audio recorders to ensure pick-up of all that was said and subsequently transcribed verbatim. When no new hypotheses or diagnoses appeared, audio recording was terminated.

Inter-rater reliability of categorisation of clinical reasoning clauses was determined by generalisability analysis. Four random samples of clauses, one from each of the groups, were independently labelled by two raters. For the pooled set of 189 clauses, $16 \%$ of all clauses, the generalisability coefficient $G$ was calculated as an indicator of the inter-rater reliability (Brennan 2001). The coefficient $G$ is defined

$$
G=\frac{\sigma_{c}^{2}}{\sigma_{c}^{2}+\frac{\sigma_{c \times r}^{2}}{n_{r}}}
$$

where $\sigma_{c}^{2}$ is the variance of the $0-1$ label clinical reasoning over clauses (the variance of interest), $\sigma_{c \times r}^{2}$ the variance of the interaction of clauses and raters (representing the disagreement between the raters), and $n_{r}$ the number of raters. Variance components $\sigma_{c}^{2}$, and $\sigma_{c \times r}^{2}$ were estimated by variance analysis of the data in the sample of clauses labelled by two raters. Then, using the equation above, the expected reliability $G$ could be calculated for any number of raters $n_{r}$. For a single rater $\left(n_{r}=1\right)$ coefficient $G$ was found to be equal to 0.77 . As this indicates a sufficient level of reliability, (Streiner \& Norman 2008) it was decided to use the labelling results obtained with a single rater. 
Table 2. Effects of bimodal presentation, buzz groups and their interaction on the odds of a clause in the discussion to be a clinical reasoning clause (analysis: logistic regression, $\mathrm{DF}=1$ ).

\begin{tabular}{|c|c|c|c|c|}
\hline Constant & 1.40 & - & - & - \\
\hline Main effect Bimodal presentation & 1.23 & 0.83 & 1.83 & $p=0.30(\mathrm{NS})$ \\
\hline Interaction Bimodal presentation + buzz groups & 1.90 & 1.15 & 3.15 & $p<0.013$ \\
\hline
\end{tabular}

aLower and Upper refer to the boundaries of the 95\% confidence interval for the odds ratio.

\section{Analyses}

For hypothesis 1 , the occurrence of clinical reasoning in the discussions was investigated by analysing the odds of a clause to be a clinical reasoning clause. For such a binary-dependent variable a logistic regression is appropriate to estimate the effects of several factors and their interaction(s). For our set-up this implies that the log odds of clinical reasoning, i.e. log (frequency of clinical reasoning clauses/frequency of other clauses) are explained by the sum of three terms: the main effects of the independent variables bimodal presentation scheme and buzz groups, and their interaction effect. The unit of analysis was clauses in the transcripts.

For hypotheses 2 and 3, a full factorial two-way ANOVA was performed with presentation scheme and buzz groups (and their interaction) as factors for perceived learning, judgment of learning and diagnostic accuracy. MannWhitney tests were also done. The unit of analysis was the participants. For all statistical tests, a significance level of 0.05 was used.

Participation was voluntary. Ethical approval was sought through the regional Danish Ethical Committee, and according to Danish regulations, the study was exempted from formal ethical approval. Strategic funds for postgraduate educational activities from the Faculty of Health, Aarhus University.

\section{Results}

Age and duration of paediatric training for participants was comparable among basic, buzz, bimodal and buzz-bimodal groups. The mean time for analyses of cases was comparable at 9.1, 10.5, 14.3 and $12.6 \mathrm{~min}$, respectively. Duration of buzz groups was $2.4 \mathrm{~min}$ (range 2.2-2.5).

Table 2 shows the results of the logistic regression in terms of the odds of clinical reasoning clauses to occur in the discussions. The constant 1.4 represents the odds for the group without bimodal presentation and buzz groups. For the group with bimodal presentation only the odds changed with a factor 1.23 (resulting odds: $1.4 \times 1.23$ ), and for the group with buzz groups only they changed with 0.95 (resulting odds: $1.4 \times 0.95$ ), however, both effects were found to be nonsignificant. As expected, the combined use of bimodal presentation and buzz groups caused a significant interaction effect, increasing the odds for the corresponding group by a factor of $1.9(p=0.013)$ from 1.4 to 2.7 ; see Table 2 and Figure 3.

This study shows that a combined bimodal presentation and buzz group discussion of emergency cases improves

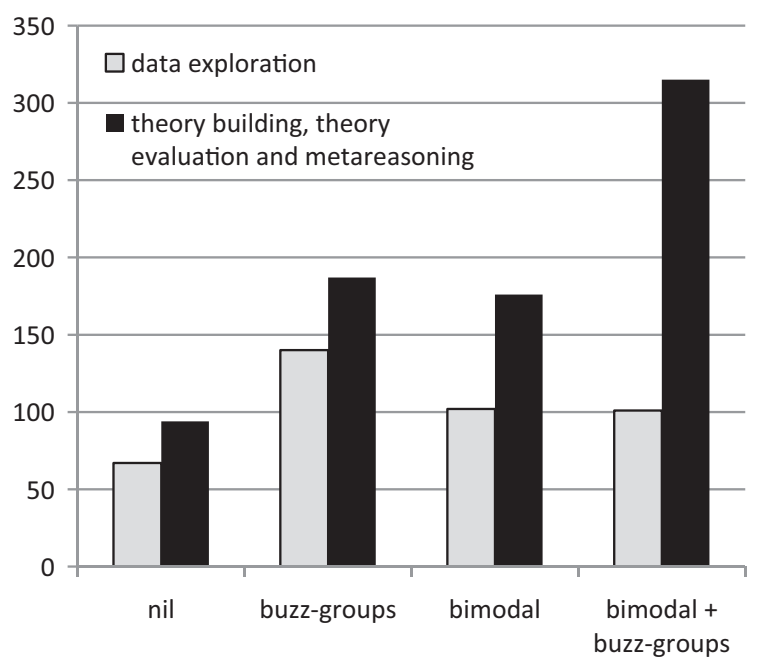

Figure 3. Frequencies of clinical reasoning in the four groups. Combined bimodal presentation and use of buzz groups resulted in much higher frequencies of desirable clinical reasoning processes: theory building, theory evaluation and meta-reasoning, while data exploration was limited.

participants' clinical reasoning during morning report. These results suggest that participants are able to reason like experts if they have a bimodal presentation available when active in buzz groups. This combined approach results in enhanced clinical reasoning. Our first hypothesis was therefore supported.

Not surprisingly, the perceived learning from discussion of cases was generally much lower among specialists than among the residents (Table 3). A main positive effect of bimodal presentation was, however, noted with the specialists with regard to perception of learning (2.5 increase on a 10-point scale, $p<0.05)$. A strong positive effect of buzz groups was found among the residents on judgment of learning, i.e. the prediction of future performance (3.9 increase on a 20-point scale, $p<0.005)$. Our second and third hypotheses were therefore partly supported.

A main positive effect of bimodal presentation was noted among the specialists with regard to diagnostic accuracy $(2.5$ increase on a 20 -point scale, $p<0.05$ ). This suggests that the specialists were not only superior in combining information from the bimodal presentation of cases, they subsequently also performed better at the diagnostic accuracy test. Our fourth hypothesis suggested an improvement in diagnostic accuracy, and this was supported for the specialists. 
Table 3. Main effects found in a full factorial ANOVA on perceived learning, judgment of learning and diagnostic accuracy for residents and specialists concerning bimodal presentation and buzz groups.

\begin{tabular}{|c|c|c|c|c|c|c|c|c|c|c|}
\hline \multirow[b]{3}{*}{ Participants } & \multirow[b]{3}{*}{ Factor } & \multicolumn{9}{|c|}{ Dependent variable } \\
\hline & & \multicolumn{3}{|c|}{ Perceived learning } & \multicolumn{3}{|c|}{ Prediction of diagnostic accuracy performance } & \multicolumn{3}{|c|}{ Diagnostic accuracy } \\
\hline & & $M^{a}$ & $S D^{b}$ & effect size ${ }^{c}$ & M & SD & effect size & M & SD & Effect size \\
\hline \multirow[t]{6}{*}{ Residents } & Bimodal & & & & & & & & & \\
\hline & No & 7.0 & 1.1 & -1.2 & 12.5 & 2.3 & -0.2 & 16.5 & 2.1 & 0.1 \\
\hline & Yes & 5.7 & 2.0 & & 12.0 & 2.4 & & 16.8 & 1.6 & \\
\hline & Buzz & & & & & & & & & \\
\hline & No & 6.2 & 2.1 & 0.1 & 10.3 & 0.8 & $4.9^{* * *}$ & 16.7 & 2.0 & 0.0 \\
\hline & Yes & 6.5 & 1.2 & & 14.2 & 1.3 & & 16.7 & 1.8 & \\
\hline \multirow[t]{6}{*}{ Specialists } & Bimodal & & & & & & & & & \\
\hline & No & 1.0 & 1.1 & $2.3^{*}$ & 15.0 & 1.9 & 0.4 & 15.8 & 1.6 & $1.4^{*}$ \\
\hline & Yes & 3.5 & 1.8 & & 15.8 & 2.0 & & 18.0 & 1.3 & \\
\hline & Buzz & & & & & & & & & \\
\hline & No & 1.8 & 1.8 & 0.5 & 14.8 & 2.1 & 0.6 & 16.7 & 1.0 & 0.5 \\
\hline & Yes & 2.7 & 2.1 & & 16.0 & 1.7 & & 17.2 & 2.4 & \\
\hline
\end{tabular}

$* p<0.05$

${ }^{* *} p<0.005 ;{ }^{a}$ mean; ${ }^{b}$ standard deviation; ${ }^{\mathrm{c} C o h e n ' s ~} d:\left(\mathrm{M}_{\text {yes }}-\mathrm{M}_{\mathrm{no}}\right) / \mathrm{SD}_{\mathrm{no}}$.

\section{Discussion}

With regard to our first research hypothesis, the combined use of bimodal presentation and buzz groups increased the quality of clinical reasoning in the discussion. We have therefore shown that the interaction in the buzz groups is greatly helped by non-transient information available in written form throughout the discussion. The quality of clinical reasoning improved markedly. This process is likely to enhance encapsulation, illness script formation and expertise. It is important to note that the study also showed that the addition of bimodal presentation only or addition of buzz groups only, did not greatly improve clinical reasoning.

The improved quality of clinical reasoning associated with use of a combination of bimodal presentation and buzz group analysis of new, authentic cases may be related to a reduced cognitive load. With bimodal presentation available, the cognitive processes can focus on the building and evaluation of hypotheses. If a written case is not available, many clinical reasoning processes will be spent on data exploration rather than on more desirable building or evaluation of the hypotheses. The resulting diffuse discussion may cause frustration and/or opposition among participants in a busy clinical situation like the morning report. This is an example of the modality effect (van Merriënboer \& Sweller 2010). The multimodal presentation reduces extraneous cognitive load by use of both the visual and auditory processor of working memory and then again improve the quality of clinical reasoning.

The results suggest that the deliberate practice in TDC designed to guide participants to use efficient visual problem solving strategies in combination with buzz group interaction prior to making management plans will indeed help learners approach cases with a top-down, forward method.

With regard to the second hypothesis, a positive effect of bimodal presentation on perceived learning was noted among the specialists, but not the residents. This might suggest that 764 the specialists with better prior knowledge were better able to interpret the bimodal information and the following large group discussion and to modulate illness scripts. Interestingly, with regard to the third hypothesis, a strong main effect of buzz groups was found among the residents on judgment of learning. This suggests that residents were strongly influenced by the modelling, coaching and scaffolding offered by the paediatric specialists. No immediate improvement, however, was seen in residents' diagnostic accuracy. This finding confirms that learners can be misled as to whether learning has been achieved, sometimes resulting in overconfidence (Bjork et al. 2013). The subjective judgment of learning can reflect priming instead of immediate acquirement of usable diagnostic skills.

With regard to the fourth hypothesis, a positive effect of bimodal presentation on diagnostic accuracy was noted among the specialists. This suggests that the specialists not only perceive relatively more learning with bimodal presentation of cases: they are better able to combine the written and the oral information resulting ultimately in higher diagnostic accuracy. They are able to develop their expertise by integrating new knowledge into their illness scripts and to actually apply those (Schmidt \& Rikers 2007). On the other hand, the residents possess less knowledge encapsulated as illness scripts, and additional time and effort is required for encapsulation to occur (Schmidt \& Rikers 2007). Thus, the results suggest that extra efforts are necessary to improve learning outcomes for the residents. One such effort could be a specialist thinking aloud and relating what steps he or she would take to make a diagnosis after the analyses in the group (Balslev et al. 2010). This might deepen the residents' understanding and enhance the diagnostic accuracy. Feedback about the clinical course, work-up and treatment of TDC on subsequent morning reports along with selfdirected learning efforts is extremely relevant and may aid clinicians to develop new illness scripts on a long-term basis. 
Judgment of learning, i.e. prediction of how well residents would perform on the diagnostic accuracy test, was significantly increased by buzz groups. This is a remarkable effect and may illustrate how self-assessment abilities are very often uncorrelated with actual performance measures (Bjork et al. 2013). The increased judgment of learning may reflect beliefs or even overconfidence in one's diagnostic abilities that can occur after discussing a case with a senior colleague (Bjork et al. 2013). This represents an important result for clinical learners and teachers, because it shows that instruction has effects on how students perceive and regulate their learning. As alluded to above, the subjective judgment of learning can reflect priming, which can be followed by later learning of usable diagnostic skills.

As there is little or no evidence for the utility in education of perceived learning styles (Pashler et al. 2008), we do not believe that differences in learning styles might affect the results of this randomized controlled study.

The main strength of this study is the controlled, randomised design, with interaction among specialists and residents directly involved in clinical paediatrics on a daily basis. It is important to note that this study simulates working conditions in paediatric departments as none of the participants knew the diagnoses of the cases beforehand. The specialists had to diagnose cases concurrently with modelling, coaching and scaffolding the unfolding diagnostic process. Thus, the residents were able to participate in ongoing, diagnostic processes. It is also a strong point that all of the groups in the study used stepwise approaches to presentation and analysis of cases, because stepwise approaches will help participants apply a top-down and forward approach focusing on the important symptoms first. As this randomised study was designed to compare the four groups, the differences in the dependent variables must be caused by the treatments given in buzz, bimodal or buzz-bimodal groups. We believe that our approach to measurement of clinical reasoning is valid, as it includes evaluation of correct as well as faulty theories (de Grave et al. 1996). The discussion of contrasting theories might indeed stimulate learning (Ark et al. 2007).

Some shortcomings of the present study must be kept in mind. Firstly, this study focuses on immediate learning effects, and we therefore lack information on learning effects that may appear over the long term. The number of participants was small, i.e. 24 clinicians, and half of these were trainees. However, because the size of some of the resulting effects was quite large (effect size 1.4 to 4.9 ) it was still possible to achieve statistical significance for a number of major effects, despite the relatively low numbers of subjects in the study. Still, these numbers were not sufficient to allow the detection of effects of moderate size (effect size 0.4 to 0.6 ) or lower in the current study. Therefore we believe that the major effects that are found significant in this study can be generalized to other medical training programs, but then again we may have missed some of the smaller effects.

Medical students regularly participate in morning report. Unfortunately, due to restrictions in simultaneous audio recording of multiple buzz-groups with more than two participants, we were unable to include medical students along with the residents and specialists in the buzz groups. It is however most likely that positive effects on clinical reasoning might also be seen with medical students.

We and colleagues at a number of paediatric departments in Denmark restructured and modified morning report by daily, (A) bimodal presentation, and (B) buzz group discussion of a single selected case. Importantly, we added (C) a final wrap-up clinical reasoning remark by one of the specialists to help the trainees direct their learning further (Kassirer 2010). This three-step procedure is readily implemented, it is extremely sought after, and an upper time limit at $10 \mathrm{~min}$ is applied. We recommend this procedure as a regular agenda item at morning report to improve clinical reasoning and learning.

\section{Notes on contributors}

THOMAS BALSLEV, MD, MHPE, $\mathrm{PhD}$, is a consultant in paediatric neurology at Viborg Regional Hospital and an Associate Professor at Aarhus University. His research focuses on authentic, collaborative learning.

ASTRID BRUUN RASMUSSEN, MD, is a paediatric resident at Viborg Regional Hospital.

TORJUS SKAJAA, MD, PhD, is a paediatric resident at Viborg Regional Hospital.

JENS PETER NIELSEN, MD, is a consultant in paediatrics and coordinator of postgraduate education at Viborg Regional Hospital.

ARNO MUIJTJENS, PhD, is an Associate Professor and Statistician-methodologist, at Department of Educational Development and Research. Faculty of Health Medicine and Life Sciences, Maastricht University.

WILLEM DE GRAVE, PhD, is a Senior Lecturer and Educational Psychologist in the Department of Educational Development and Research. Faculty of Health Medicine and Life Sciences, Maastricht University,

JEROEN VAN MERRIËNBOER, PhD, is a Professor, Experimental Psychologist and Research Director, at the School of Health Professions Education (SHE), Maastricht University.

\section{Acknowledgments}

We thank the participating residents and specialists in paediatrics department. We also thank Edwin Stanton Spencer for linguistic assistance.

Declaration of interest: The authors report no declarations of interest.

\section{References}

Amin Z, Guajardo J, Wisniewski W, Bordage G, Tekian A, Niederman LG. 2000. Morning report. Focus and methods over the past three decades. Acad Med 75:S1-S5.

Ark TK, Brooks LR, Eva KW. 2007. The benefits of flexibility: The pedagogical value of instructions to adopt multifaceted diagnostic reasoning strategies. Med Educ 41:281-287.

Balslev T, de Grave W, Muijtjens AMM, Eika B, Scherpbier AJJA. 2009. The development of shared cognition in paediatric residents. Adv Health Prof Educ 14(4):557-565.

Balslev T, de Grave W, Muijtjens AMM, Scherpbier AJJA. 2010. Enhancing diagnostic accuracy among non-experts by use of video-cases. Pediatrics 125(3):e570-e576 
Balslev T, Jarodzka H, Holmqvist K, de Grave W, Muijtiens AMM, Eika B, van Merriënboer J, Scherpbier AJJA. 2012. Visual expertise in paediatric neurology. Eur J Paediatr Neurol 161(2):161-166.

Belland BR. 2014. Scaffolding: Definition, current debates and future directions. In: Spector JM, Merrill MD, Elen J, Bishop MJ, editors. Handbook of research on educational communications and technology. New York, USA: Springer Science; Business Media. pp 505-518.

Bjork RA, Dunlosky J, Kornell N. 2013. Self-regulated learning: Beliefs, techniques and illusions. Annu Rev Psychol 64:417-444.

Brennan RL. 2001. Generalizability theory. New York, USA: Springer Verlag.

Cantillon P. 2003. ABC of learning and teaching in medicine: Teaching large groups. BMJ 326:437.

Collins A. 2006. Cognitive apprenticeship. In: Sawyer RK, editor. The Cambridge handbook of the learning sciences. Cambridge, UK: Cambridge University Press. pp 47-60.

DeAngulus M, Pelz JB. 2009. Top-down control of eye movements: Yarbus revisited. Visual Cognition 17:790-811.

de Grave WS, Boshuizen HPA, Schmidt HG. 1996. Problem based learning: Cognitive and metacognitive processes during problem analysis. Instruct Sci 24:321-341.

Eva KW, Regehr G. 2005. Self-assessment in the health professions: A reformulation and research agenda. Acad Med 80(suppl. 10): S46-S54.

Klaber RE, Macdougall CF. 2009. Maximising learning opportunities in handover. Arch Dis Child Educ Pract Ed 94:118-122.

Gross GP, Donnelly GB, Reisman AB, Sepkowitz KA, Callahan MA. 1999. Resident expectations of morning report. A multi-institutional study. Arch Intern Med 159:1910-1914.

Hassebrock F, Prietula MJ. 1992. A protocol-based coding scheme for the analysis of medical reasoning. Int J Man-Machine Stud 37:613-652.

Houghtalen RP, Olivares TM, Green Y, Booth H, Conwell Y. 2002 Residents' morning report in psychiatry training. Description of a model and a survey of psychiatry training. Acad Psychiatry 26:9-16.

Itti L, Koch C. 2001. Computational modelling of visual attention. Nat Rev Neurosci 2:194-203.

Jaques D. 2003. ABC of learning and teaching in medicine. Teaching small groups. BMJ 26:492-494.

Jarodzka H, Balslev T, Holmqvist K, Scheiter K, Nyström M, Eika B, Gerjets P. 2012. Conveying clinical reasoning based on visual observation via eye-movement modelling examples. Instruct Sci 40(5):813-827.

Kassirer JP. 2010. Teaching clinical reasoning: case-based and coached. Acad Med 85(7):1118-1124.
Kok E, de Bruin ABH, Robben SGF, van Merriënboer JJG. 2012. Looking in the same manner but seeing it differently: Bottom-up and expertise effects in radiology. Appl Cognit Psychol 26:854-862.

Krupinski EA, Tillack AA, Richter L, Henderson JT, Bhattacharyya AK, Scott KM, Graham AR, Descour MR, Davis JR, Weinstein RS. 2006. Eye movement study and human performance using telepathology virtual slides. Implications for medical education and differences with experience. Hum Pathol 37(12):1543-1556.

Lebeau RB. 1998. Cognitive tools in a clinical encounter in medicine: Supporting empathy and expertise in distributed systems. Educ Psychol Rev 10:3-24.

McNeill M, Ali SK, Banks DE, Mansi IA. 2013. Morning report: Can an established medical education tradition be validated? J Grad Med Educ 5(3):374-384.

Morris C, Blaney D. 2010. Workbased learning. In: Swanwick T, editor. Understanding medical education. Oxford: Wiley-Blackwell. pp 69-82.

Pashler H, McDaniel M, Rohrer D, Bjork R. 2008. Psychological science in the public interest. Learning styles. Concepts Evidence 9(3):105-119.

Puntambekar S, Hübscher R. 2005. Tools for scaffolding students in a complex learning environment: What have we gained and what have we missed? Educ Psychol 40(1):1-12.

Schmidt HG, Rikers RMJ. 2007. How expertise develops in medicine: Knowledge encapsulation and illness script formation. Med Educ 41: 1133-1139.

Schumacher DJ, Englander R, Carraccio C. 2013. Developing the master learner: Applying learning theory to the learner, the teacher and the learning environment. Acad Med 88(1):1635-1645.

Streiner DL, Norman GR. 2008. Health Measurement Scales: A practical guide to their development and use. Oxford: Oxford University Press.

van Merriënboer JJG, Sweller J. 2005. Cognitive load theory and complex learning: Recent developments and future directions. Educ Psychol Rev 17(2):147-177.

van Merriënboer JJG, Sweller J. 2010. Cognitive load theory in health professional education: Design principles and strategies. Med Educ 44: 85-93.

van Meeuwen LW, Jarodzka H, Brand-Gruwel S, Kirschner PA, de Bock JJPR, van Merriënboer JJG. 2014. Identification of effective visual problem solving strategies in a complex visual domain. Learn Instr 32: $10-21$.

Walton JM, Steinert Y. 2010. Patterns of interaction during rounds: Implications for work-based learning. Med Educ 44:550-558.

Yarbus A. 1967. Eye movements and vision. New York, USA: Plenum Press. 